\title{
Primary Percutaneous Coronary Intervention in the Left Main ST-Elevation Myocardial Infarction and Cardiogenic Shock on Octogenarian Patient with Single Remaining Vessel
}

\author{
Mochamad Yusuf Alsagaff* (D), Kandita Arjani(D), Yudi Her Oktaviono (D), Sondang Jasmine Sitorus (D) \\ Department of Cardiology and Vascular Medicine, Faculty of Medicine, University of Airlangga, Surabaya, Indonesia
}

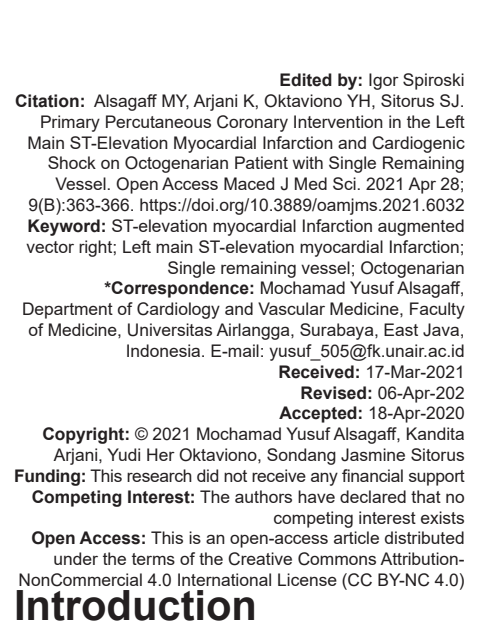

The left main coronary artery (LMCA) ST-elevation myocardial infarction has been associated with significant morbidity and mortality. The LMCAculprit lesions in acute coronary syndrome usually present with hemodynamic instability and cardiogenic shock [1]. Older age and cardiogenic shock are independent predictors for in-hospital mortality [2]. Octogenarian people with acute myocardial infarction (AMI) mostly get conservative strategy, although guideline may proceed to myocardial revascularization [3]. Here, we report a case of total LMCA occlusion complicated by cardiogenic shock in an octogenarian that was saved by stenting in thrombolysis in myocardial infarction Flow III right coronary artery (RCA). This case highlights a rare case of STEMI in a single remaining vessel.

\section{Case Report}

An 84-year-old Javanese man with a risk factor of smoking was referred to our emergency unit with STEMI on augmented vector right (aVR) Killip IV and new-onset RBBB. The patient complained of typical chest pain and had been treated for 8 days at the local hospital. However, the symptoms worsen and become persistent in day 9 of hospitalization. Patients had received $2.5 \mathrm{mg}$ of subcutaneous fondaparinux for 5 days, $75 \mathrm{mg}$ of clopidogrel, $2.5 \mathrm{mg}$ of bisoprolol, $20 \mathrm{mg}$ of atorvastatin, and $100 \mathrm{ng}$ norepinephrine/min through continuous pump. On admission, the blood pressure was $97 / 64 \mathrm{mmHg}$ with support of $100 \mathrm{ng}$ norepinephrine/ min continuous infusion, heart rate 104 beats/min (bpm), respiratory rate 24 times/min, and oxygen saturation of $96 \%$ with $\mathrm{O}_{2}$ supplementation of $6 \mathrm{l} / \mathrm{min}$ on a simple mask.

Electrocardiogram showed sinus tachycardia, 104 bpm, and left axis deviation, with ST elevation in aVR and incomplete RBBB (Figure 1). Laboratory tests showed an increment of cardiac markers with CKMB of $23.7 \mathrm{U} / \mathrm{L}$ and troponin-I of $8.26 \mathrm{ng} / \mathrm{ml}$. From transthoracal echocardiography, we found mild mitral, aortic, and mild tricuspid regurgitation without thrombus or vegetation. There was a decrease in systolic left ventricular (LV) function (EF Teich 41\%), with diastolic LV function LV pseudonormal, and normal systolic RV function. There was hypokinetic in anteroseptal BM, inferoseptal BM, septal A, and 
anterior BMA from LV segmental analysis. No LV hypertrophy was found.

\begin{tabular}{ll}
\hline Laboratories value & \\
\hline Leukocytes & 10,110 \\
Hemoglobin & 11.8 \\
Platelets & 145,000 \\
Serum glutamic-oxaloacetic transaminase/serum & $43 / 29$ \\
glutamic pyruvic transaminase & \\
Albumin & 1.19 \\
Creatinine & 0.78 \\
BUN & 68 \\
CK-MB & 23.7 \\
Blood sugar & 213 \\
Natrium & 140 \\
Kalium & 4.3 \\
Chloride & 100 \\
Troponin-I & 8.26 \\
Triglycerides /total cholesterol & $75 / 129$ \\
\hline
\end{tabular}

Emergency coronary angiography was obtained and resulted in ostial left main chronic total occlusion (Figure 2). There was a significant stenosis (90\%) in distal RCA (Figure 3) with Grade II collateral perfusion from RCA to LCA (Figure 4). We tried to open the culprit lesion at first. However, the guiding catheter failed to engage in the LCA. Based on those findings, an emergency bypass was planned for complete revascularization, and intra-aortic balloon pump (IABP) was implanted during the procedure due to hemodynamic instability (Figure 5). The patient case was then discussed within the heart team, and we decided to open up RCA, as it will simplify the complicated procedure.

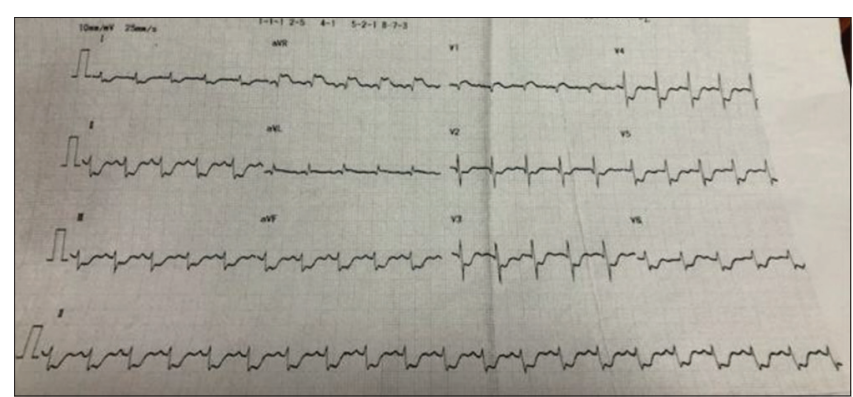

Figure 1: An electrocardiogram shows ST elevation in leads augmented vector right and ST depression in all

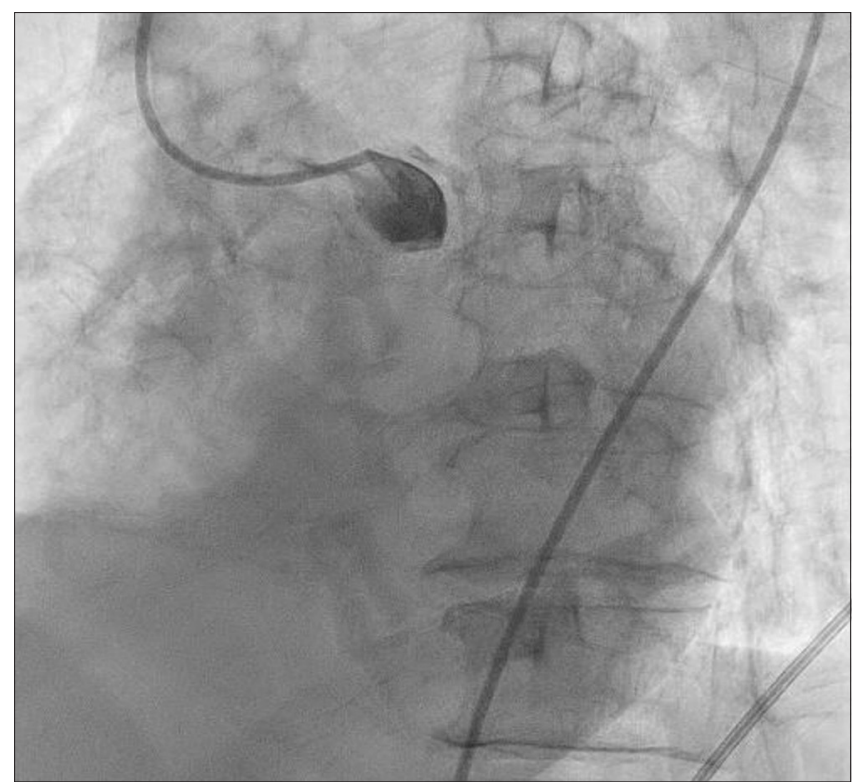

Figure 2: Coronary angiogram at the first attempt showed total occlusion in ostial left main coronary artery
Considering that the RCA was the single remaining vessel that perfused all part of the threatening myocardium, we execute quick direct stenting on the RCA. It was a pristine procedure followed by an immediate improvement in the patient's symptoms and hemodynamic. Within $24 \mathrm{~h}$, IABP and vasoactive drugs were weaned. The patient was discharged 7 days after percutaneous coronary intervention $(\mathrm{PCl})$ procedure with optimal medical therapy (100 mg of aspirin, $75 \mathrm{mg}$ of clopidogrel, $40 \mathrm{mg}$ of atorvastatin, $2.5 \mathrm{mg}$ of bisoprolol, $5 \mathrm{mg}$ of ramipril, $5 \mathrm{mg}$ of isosorbide dinitrate, $40 \mathrm{mg}$ of furosemide, and $25 \mathrm{mg}$ of spironolactone).

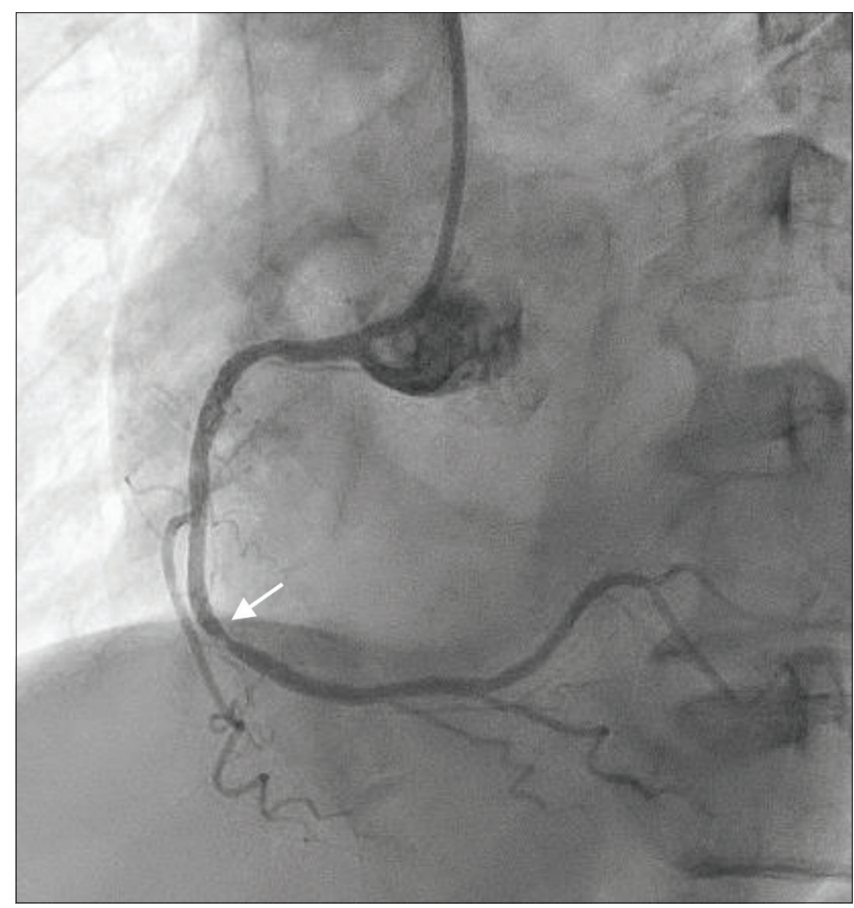

Figure 3: From the left anterior oblique view, there was critical stenosis $90 \%$ on distal right coronary artery (white arrow).

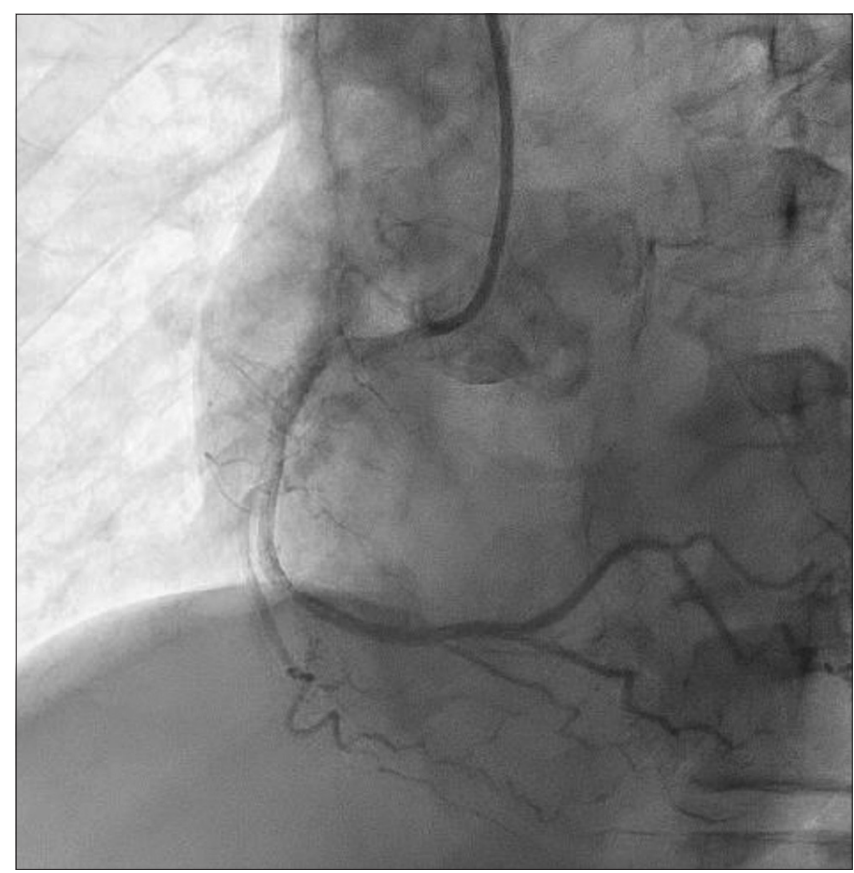

Figure 4. There was collateral from mid right coronary artery to distal left anterior descending 


\section{Discussion}

The LMCA ST-elevation myocardial infarction has been associated with significant morbidity and mortality [1], due to circulatory failure and malignant tachyarrhythmia [4]. These patients' clinical picture is predominantly catastrophic compared to a more distal coronary artery occlusion, as they usually present with sudden cardiac death or profound cardiogenic shock [5]. On the other hand, the elderly become a negative prognostic factor of AMI survival and tend to be treated less aggressively compared to the young [6].

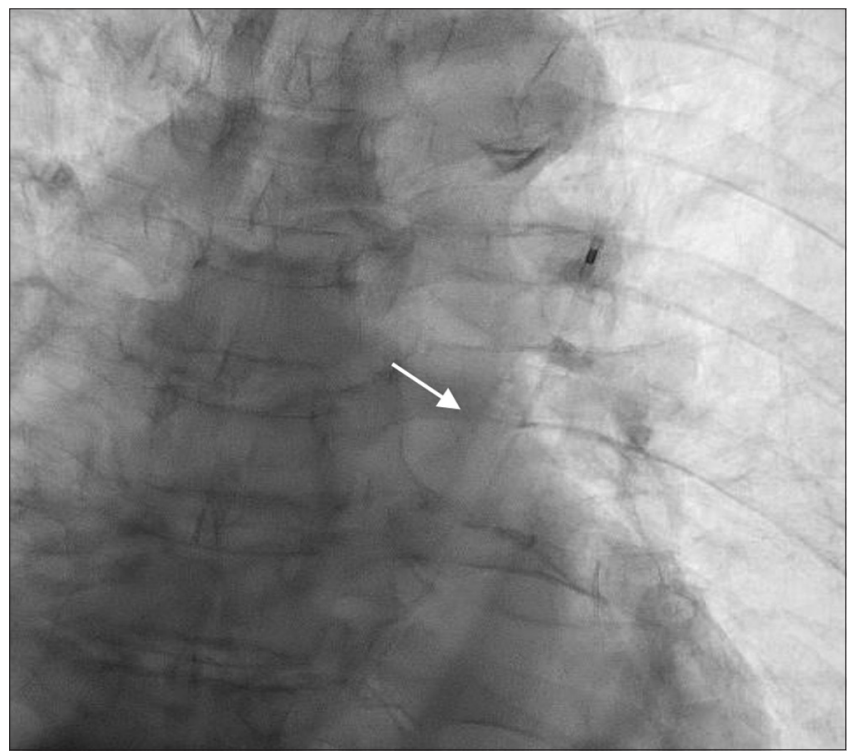

Figure 5. Intra-aortic balloon pump was inserted (white arrow)

Grygier et al. reported the left main occlusion in an 80-year-old woman. The patient also presenting with acute myocardial infarction complicated by cardiogenic shock due to the left main occlusion, then successful percutaneous intervention has been done to stabilize until bypass grafting was performed and resulted improvement of the patient [7].

We reported a case of an octogenarian patient diagnosed as a leftmain STEMI with clinical presentations of typical chest pain and cardiogenic shock. Emergency angiography was performed and revealed chronic total occlusion in ostial LMCA. There was a single remaining vessel RCA with significant stenosis $(90 \%)$ on the distal and collateral Grade II from RCA to LCA. As a surrogate blood supply, the coronary collaterals rescue the myocardium jeopardized by abruptly occluded arteries, preventing myocardial necrosis and favoring recovery after revascularization [7]. This is a rare case of how a person can be survived by perfusion on a single remaining coronary artery through the collateral's blood flow.

In the first attempt, we failed to engage the left main culprit lesion and decided to plan coronary artery bypass grafting (CABG) for complete revascularization. During this procedure, we inserted
IABP for hemodynamic support while waiting for the definitive treatment. Even though the evidence is limited regarding IABP's benefit, it should be considered as a rescue therapy to stabilize the patient and preserve organ oxygenation [8]. Regardless of CABG established as the standard management for stable LMCA disease, hesitancy encloses the optimal revascularization strategy for patients with STEMI and LMCA occlusion who survived to hospitalization, and treatment guidelines in this scenario are vague. $\mathrm{PCl}$ is technically feasible in most patients with myocardial infarction. It should be taken into account as a viable alternative to $C A B G$ for specific indications, including those with LMCA occlusion and cardiogenic shock, as witnessed in our patient [9]. For those reasons, we changed the plan and performed a second attempt $\mathrm{PCl}$ to open the single remaining artery, as the recent guideline recommends it, in the case of STEMI on cardiogenic shock [10]. After direct stenting in distal $\mathrm{RCA}$, we found an augmentation of collateral blood flow and clinical improvement on patient symptoms and hemodynamic profile.

This is a rare case of an octogenarian patient with STEMI in the left main that was successfully saved by $\mathrm{PCl}$ on the non-infarct related, single remaining RCA. An aggressive approach is compulsory in lifethreatening conditions, even in the elderly, as one life matters.

\section{Conclusion}

$\mathrm{PCl}$ can be a safe option in an elderly with single remaining vessel STEMI complicated by cardiogenic shock.

\section{References}

1. Yeo KK, Singh G, Chua K, Yap J, Armstrong E, Waldo SW, et al Left main coronary artery st-elevation myocardial infarction: clinical characteristic and outcomes from a multicenter registry. J Am Coll Cardiol. 2014;63(Suppl 12):A158. https://doi. org/10.1016/s0735-1097(14)60158-3

2. Granger CB, Goldberg RJ, Dabbous O, Pieper KS, Eagle KA CannonCP, etal. Predictors ofhospital mortality in the global registry of acute coronary events. Arch Intern Med. 2003;163(19):234553. https://doi.org/10.1001/archinte.163.19.2345

PMid: 14581255

3. Al Kindi H, Samaan A, Hosny H. Noble and excel: The debate for excellence in dealing with left main stenosis. Glob Cardiol Sci Pract. 2018;2018(1):3. https://doi.org/10.21542/gcsp.2018.3 PMid:29644230

4. Baek JY, Seo SM, Park HJ, Kim PJ, Park MW, Koh YS, et al. Clinical outcomes and predictors of unprotected left main stem culprit lesions in patients with acute ST segment 
elevation myocardial infarction. Catheter Cardiovasc Interv. 2014;83(7):E243-50. https://doi.org/10.1002/ccd.23420

PMid:22105969

5. Kanic V, Vokac D, Granda S. Acute total occlusion of the left main coronary artery treated with percutaneous intervention and simultaneous implantation of intra-aortic balloon pump. Clin Case Rep. 2017;5(12):2088-92. https://doi.org/10.1002/ccr3.1227 PMid:29225863

6. Bhatia LC, Naik RH. Clinical profile of acute myocardial infarction in elderly patients. J Cardiovasc Dis Res. 2013;4(2):107-11.

PMid:24027366

7. Grygier M, Araszkiewicz A, Lesiak M, Grajek S. Acute Myocardial Infraction in an 80 year-old woman caused by left main occlusion with concomitant chronic total occlusions: Successful treatment with percutaneous revascularization. Cardiol J. 2009;16(6):568-72.

PMid: 19950095

8. Wang B, Han YL, Li Y, Jing QM, Wang SL, Ma YY, et al.
Coronary collateral circulation: Effects on outcomes of acute anterior myocardial infarction after primary percutaneous coronary intervention. J Geriatr Cardiol. 2011;8(2):93-8. https:// doi.org/10.3724/sp.j.1263.2011.00093

PMid:22783292

9. Ibanez B, James S, Agewall S, Antunes MJ, Bucciarelli-Ducci C, Bueno $\mathrm{H}$, et al. 2017 ESC Guidelines for the management of acute myocardial infarction in patients presenting with ST-segment elevation. Eur Heart J. 2018;39(2):119-77. https:// doi.org/10.5603/kp.2018.0041

PMid:28886621

10. Lee MS, Bokhoor P, Park SJ, Kim YH, Stone GW, Sheiban I, et al. Unprotected left main coronary disease and ST-segment elevation myocardial infarction: A contemporary review and argument for percutaneous coronary intervention. JACC Cardiovasc Interv. 2010;3(8):791-5. https://doi.org/10.1016/j. jcin.2010.06.005

PMid:20723848 